\section{EXTREME HYDROLOGY}

The annual snowmelt and rainfall that feeds

California's streams and rivers is highly variable.

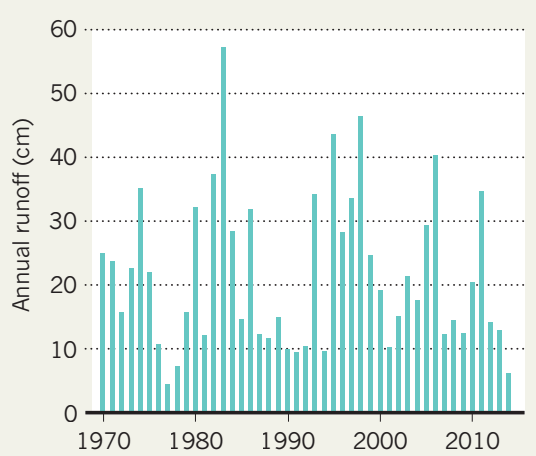

- "These are the kinds of things that can have a lasting effect on a predator species."

Teasing out the drought's effects on terrestrial animals is tougher. Researchers have documented drops in various California bird populations this year, such as mallard ducks (Anas platyrynchos) and tricolor blackbirds (Agelaius tricolor). But many other factors especially habitat loss - also come into play, so it becomes hard to isolate the effects of drought.

The drought's effects on larger animals such as bears are also uncertain. Anecdotal reports suggest that more bears than usual are showing up closer to people this year, says Jason Holley, a wildlife biologist at the California Department of Fish and Wildlife in Rancho Cordova. Within the space of six weeks this spring, four black bears appeared along the Sacramento River corridor, much farther out of the mountains than normal. "Those sorts of calls definitely pique your interest," says Holley, who thinks that dry conditions in the mountains might be pushing bears closer to populated areas.

The longest-lasting effect could be on California's forests, including its iconic giant sequoias. The drought has handed forest ecologists an unplanned experiment, says Phillip van Mantgem, a forestry expert at the USGS in Arcata, California, who is speaking at the Sacramento meeting.

Researchers are gathering data to examine whether thinning of plots in the forest, in part to reduce fire risk, might help trees do better under drought. Tests may also help to reveal the main mechanisms by which drought kills different tree species, whether by interrupting the flow of water within the tree or by starving it. "I'm really curious to see how this turns out," van Mantgem says.

There should be plenty of time to gather data. Climatologists expect an El Niño weather pattern to form in the Pacific this year, which usually brings more rain and snow to parts of California (see Nature 508, 20-21; 2014). But the pending El Niño looks to be weaker than first expected, and may not have much, if any, influence on ending the drought. Chances are that the state will remain dry well into 2015.

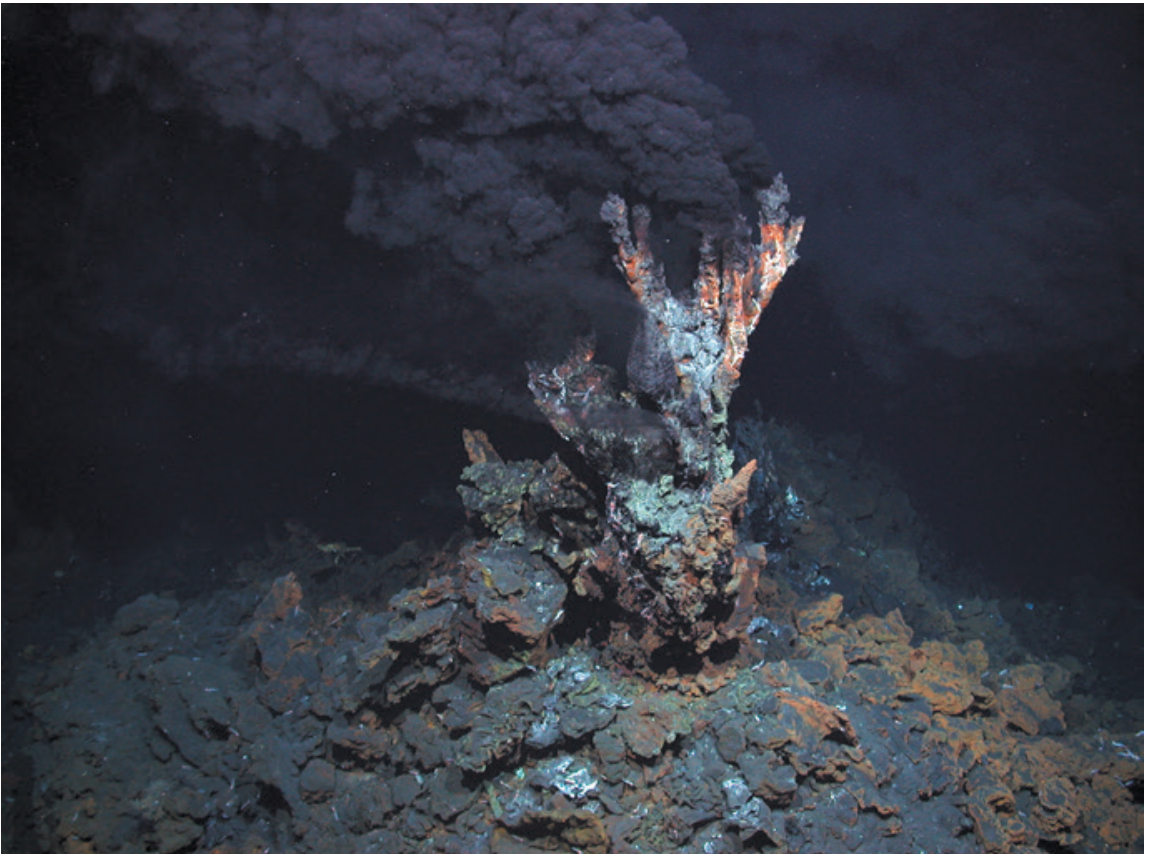

Marine communities living near mining targets such as hydrothermal vent fields might be at risk.

\title{
MARINE SCIENCE
}

\section{Health check for deep-sea mining}

\section{European project evaluates risks to delicate ecosystems.}

\section{BY KATIA MOSKVITCH}

A s commercial plans to exploit mineral resources on deep-ocean beds gather pace, marine researchers are increasingly concerned about the damage such projects might cause to the sensitive and little-understood ecosystems that thrive there. Now, scientists are taking to the sea as part of a three-year, $€ 12$-million (US\$16million) project designed to address these concerns and to develop a set of guidelines for industry.

The latest research expedition of the Managing Impacts of Deep-sea Resource Exploitation (MIDAS) programme returned to France earlier this month after exploring the Lucky Strike region of the Mid-Atlantic Ridge near the Azores islands. There, a research team began investigating whether plumes of particles that might arise from future mining operations near hot hydrothermal vents - often rich sources of metals - could affect the creatures that live there, such as deep-sea mussels.

"The goal of our experiment is to test the effects of sulphide particle deposits on the structure - composition, density, biomass, diversity - of the dominant hydrothermal fauna of the Lucky Strike vent field," says Jozée Sarrazin, a deep-sea ecologist at the French Research Institute for Exploitation of the Sea (IFREMER) in Plouzané, France, who is leading the expedition. "It should help us to propose management strategies to help protect the unique fauna associated with high-temperature emissions on the sea floor."

Resources such as polymetallic sulphides exist in large quantities around deep-sea hydrothermal vents. The idea of mining them was first mooted in the 1960s, but only now, with land sources declining and demand rising, is it being seriously explored.

Although no mining projects are yet under way, Nautilus Minerals of Toronto, Canada, has received a green light from the government of Papua New Guinea to mine about 50 kilometres offshore in the Bismarck Sea, at a depth of 1.6 kilometres. Other concessions have been awarded in the eastern Pacific Ocean. Nautilus would use sea-floor trawlers to cut or scoop up the deposits, which are then pumped up to a support ship.

The effects of such mining are cause for concern. The operations may "severely damage" the sensitive biological communities 
that live near under-sea mountains, hydrothermal vents and mineral-rich nodules on the sea floor, says David Santillo, a marine biologist and senior scientist at Greenpeace Research Laboratories at the University of Exeter, UK. As well as the physical destruction of habitats, he adds, this type of mining could smother deep-sea species with suspended plumes of sediment. Species could also be disturbed by noise, light pollution and exposure to toxic metals and other chemicals released by the mining.

The severity of such effects depends on several factors, including the nature of the exploited resource and the method of extraction, says oceanographer Cindy Van Dover, director of the Duke University Marine Laboratory in Beaufort, North Carolina. But her biggest concern is the general lack of knowledge about sea-floor processes and the cumulative effects of multiple mining events. "If we get the environmental management wrong, we are unlikely to be able to fix our mistake," she says.

The MIDAS project, which began in November, is receiving $€ 9$ million from the European Union, and includes representatives from industry and non-governmental organizations. "We will try to identify the best ways to monitor before, during and after mining to determine the total impact and recovery of the ecosystems," says Philip Weaver, managing director of Seascape Consultants in Romsey, UK, which is coordinating MIDAS.

Cruises to conduct experiments and sampling at depth form a core part of the project's work. The IFREMER cruise, on the research vessel Pourquoi Pas?, was the first stage of a two-year experiment to test the effects of sulphide plumes. The research team weighed mussels found around hydrothermal vents at a depth of 1.7 kilometres and assessed their general health. Next year, they will return and mimic the effects of particle plumes on the mussels, monitoring their reactions - for instance, death, migration or increased numbers with temperature sensors and cameras. The results of the tests will then be studied on shore.

A second MIDAS study is currently simulating potential effects on marine life in the shallow waters of Portman Bay off the coast of southeastern Spain. An onshore mining facility dumped waste into the waters there for three decades, and the researchers want to assess how the waste affected the underwater fauna. "We want to see how metal-loaded plumes behave - how far they spread, how long it takes for them to settle and so on," says marine geoscientist Miquel Canals Artigas of the University of Barcelona in Spain, who is leading the expedition.

MIDAS will submit its report to the European Commission in November 2016.

\section{NEUROSCIENCE}

\section{Teen drug use gets supersize study}

\section{US government programme will examine 10,000 adolescents to document effects on developing brains.}

\section{BY SARA REARDON}

$\mathrm{W}$ hen the states of Colorado and Washington voted to legalize marijuana in 2012, the abrupt and unprecedented policy switch sent the US National Institute on Drug Abuse (NIDA) into what its director Nora Volkow describes as "red alarm”. Although marijuana remained illegal for people under the age of 21, the drug's increased availability and growing public acceptance suggested that teenagers might be more likely to try it (see 'Highs and lows'). Almost nothing is known about whether or how marijuana affects the developing adolescent brain, especially when used with alcohol and other drugs.

The new laws, along with advances in brainimaging technology, convinced Volkow to accelerate the launch of an ambitious effort to follow 10,000 US adolescents for ten years in an attempt to determine whether marijuana, alcohol and nicotine use are associated with changes in brain function and behaviour.

At a likely cost of more than US\$300 million, it will be the largest longitudinal brain-imaging study of adolescents yet. Researchers are eager to study a poorly understood period of human development - but some question whether it is possible to design a programme that will provide useful information about the effects of drugs.

"It's definitely an idea that's overdue," says Deanna Barch, a psychologist at Washington University in St. Louis, Missouri. "The downside is it's a lot of eggs in one basket."

The exact design of the programme is still in flux. In May, NIDA held a planning meeting with the National Institute on Alcohol Abuse and Alcoholism, the National Cancer Institute

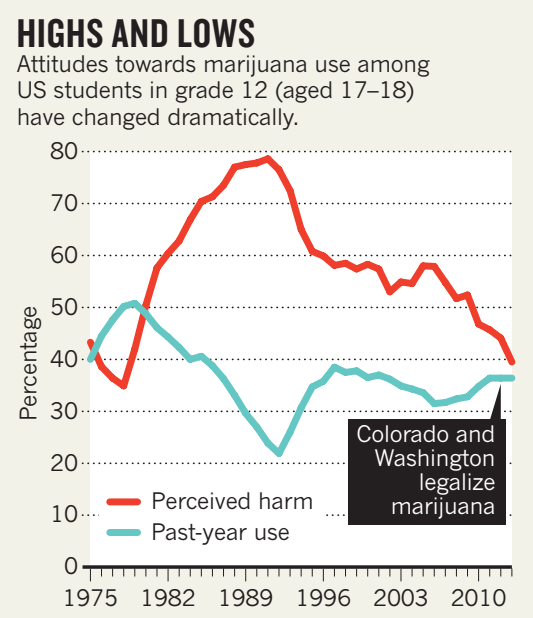

and the National Institute of Child Health and Development (NICHD), which will help to fund the project. The partners decided to recruit participants at the age of ten. Roughly every two years, researchers will image the children's brains, perform psychiatric and cognitive tests, and examine factors such as genetics and environmental exposures.

To enlist enough participants likely to use drugs, the study will recruit largely from highrisk groups, such as children of low socioeconomic status or those whose parents use drugs. Volkow says that the group plans to seek input from colleagues at November's Society for Neuroscience meeting in Washington DC before recruiting researchers for the programme.

Hugh Garavan, a psychiatrist at the University of Vermont in Burlington, says that there is much to recommend such an analysis.

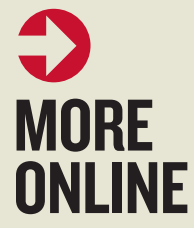

TOP STORY

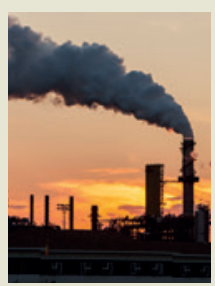

Canada-US oil pipeline could significantly increase emissions go.nature.com/ jcgw9n

\section{MORE NEWS}

- Multiple genes linked to post-traumatic stress disorder go.nature.com/anfirh - Anxiety drug helps boost survival of certain fish species go.nature.com/vbkxqg - Origami robot folds itself in 4 minutes go.nature.com/swqnz7 